\title{
Max Weber, Entre relativismo e individualismo metodológico: hacia un trabajo de aplicación conceptual al caso de los mexicanos inmigrantes de los Estados Unidos ${ }^{1}$
}

\author{
Rafael Arriaga Martínez²
}

Fecha de recepción: 1 de julio de 2013

Fecha de aprobación: 7 de noviembre de 2013

\begin{abstract}
Resumen:
En esta comunicación discutimos 1) acerca de la teoría general de la racionalidad de Raymond Boudon y la teoría de la posmodernidad de Michel Maffesoli, 2) de la lectura que ambos autores ofrecen de las nociones weberianas de desencantamiento del mundo y la guerra de los dioses, y3) de la manera particular como estas dos nociones, interpretadas distintamente, aclaran los objetos de investigación. Nos inspiramos de la problemática relativa a la presencia de inmigrantes mexicanos en los Estados Unidos para ofrecer algunos ejemplos de aplicación.
\end{abstract}

Palabras clave: razón, emoción, desencantamiento del mundo, guerra de dioses, inmigrantes

\begin{abstract}
Abstrac:
This paper discusses 1) Raymond Boudon's general theory of rationality and Michel Maffesoli's postmodernity theory, 2) the readings these two authors make of Weber's notions of disenchantment of the world and the war of gods, and 3) the way these two notions when interpreted differently may clarify the research objects. The case of the Mexican immigrants in the US offers applied examples.
\end{abstract}

Key words: reason; emotion; disenchantment of the world; the war of gods; immigrants

1 Conferencia presentada ante los alumnos del programa de maestría y doctorado del Centro de Estudios superiores de México y Centro-América (CESMECA) de la Universidad de Ciencias y Artes de Chiapas (UNICACH), el 22 de noviembre de 2012.

2 Doctor por la Universidad de Sorbonne-París IV. Instituto de Investigaciones Sociales Universidad Autónoma de Baja California, Boulevard Benito Juárez, S/N Mexicali, Baja California, México. rarriaga@uabc.edu,mx 
Max Weber, entre relativismo e individualismo metodológico: hacia un trabajo de aplicación conceptual al caso de los mexicanos inmigrantes de los Estados Unidos - Rafael Arriaga Martínez

\section{Introducción}

En este trabajo discutimos acerca de la teoría de la posmodernidad de Michel Maffesoli poniéndola en perspectiva comparativa con la teoría general de la racionalidad de Raymond Boudon. Consideramos la lectura que ambos autores ofrecen de las nociones weberianas de desencantamiento del mundo y la guerra de los dioses, de la manera particular como estas dos nociones, interpretadas distintamente, aclaran los objetos de investigación. Nos inspiramos de la problemática relativa a la presencia de inmigrantes mexicanos en los Estados Unidos para ofrecer algunos ejemplos de aplicación.

Antes de entrar propiamente a la discusión convendría explicar el método de exposición y de paso traer a colación algunos antecedentes relacionados con la biografía de Michel Maffesoli y las circunstancias que nos han llevado al estudio y la instrumentación de estas dos teorías. Como se sabe, Michel Maffesoli es un intelectual francés que ha tenido eco en muchos países, sobre todo en los países del sur, el sur de Europa y América Latina. Curiosamente, es en países como Italia, España y nuestro subcontinente en donde la emoción, la espontaneidad, la festividad, la prosémica como él dice, son mucho más palpables. Digamos que su teoría y los conceptos que estructuran su teoría corresponden a abstracciones que si bien es cierto describen aspectos de una realidad social que (Re) emergen en los países más desarrollados, estos mismos describen una sensibilidad, formas de ser que no se han perdido en nuestro continente. No ceden, en todo caso, ante los embates de la modernidad y el racionalismo que le acompaña.

Observador agudo de estas nuevas y a la vez arcaicas maneras de ser, quizás en parte porque es de origen italiano por parte de su padre, un inmigrante venido a Francia a trabajar en las minas del sur, Michel Maffesoli insiste en la necedad de los intelectuales y en particular de la intelligentsia de París, que no ven, no comprenden, no intuyen, como él dice, que entre los pliegues de la modernidad se despliega la posmodernidad. 
Michel Maffesoli es actualmente profesor de la Sorbonne, la Universidad de René Descartes-París V, y es también director del Centro de Estudios de lo Actual y lo Cotidiano (Centre d'Etudes sur l'Actuel et le Quotidien) en donde tuvimos la oportunidad de un proyecto en torno a la filiación epistemológica de Max Weber. Todo ello en el marco de una estancia de investigación posdoctoral.

Hasta entonces teníamos entendido que Max Weber participaba totalmente de esa corriente de pensamiento que Raymond Boudon llama Individualismo metodológico. Lo cual es totalmente de esperarse cuando se lee a Weber con los lentes de Boudon y se estudia a un clásico en el marco de un programa doctoral dirigido por Raymond Boudon mismo.

Pero como dice Michel Maffesoli, a Weber no se le puede reducir a una sola posición epistemológica, porque en él no todo es racionalidad. Según él, en su obra hay también lugar para una lectura holística y relativista. Naturalmente, Maffesoli no es el único intelectual que sostiene la filiación epistemológica de Weber con Nietzsche y el relativismo que lo caracteriza. Son numerosos los autores que alimentan la polémica al respecto. No obstante, para Raymond Boudon la lectura relativista que proponen todos ellos es simplemente inaceptable.

El hecho es que frente a esta controversia, tuvimos que volver a leer a Weber pero esta vez con los lentes de Maffesoli, con la teoría de la posmodernidad en la mente y confrontándolo con la lectura boudiana de Weber. Para un conocimiento más amplio sobre este punto véase mi artículo titulado Max Weber: entre el relativismo y el individualismo metodológico. Entrevista con Michel Maffesoli (Arriaga, 2012).

Más allá de la polémica en torno a la afiliación epistemológica de Max Weber, aquí el objetivo es otro: el de considerar la teoría de Michel Maffesoli desde una perspectiva comparativa y en el marco práctico de la aplicación. Creo que esa es la mejor manera de ilustrar el modus operandi de una teoría, comparándola con 
otras, y qué mejor si esta otra le es antitética, como es el caso de la teoría general de la racionalidad de Raymond Boudon.

Es pues bajo este enfoque comparativo y con este objetivo en mente que consideramos ciertos aspectos de la experiencia de los mexicanos que emigran y viven en los Estados Unidos. Por cuestiones de tiempo, nos limitaremos a unos cuantos ejemplos de aplicación y considerando sólo el pensamiento de Weber relacionado con el desencantamiento del mundo y la guerra de los dioses.

\section{Emoción versus razón}

Digamos de entrada que aquí lo fundamental es el aspecto heurístico de las teorías, en el sentido que lo que más nos interesa de ellas es su instrumentación, el manejo de los conceptos y la manera particular como aclaran los fenómenos sociales. En este sentido la teoría de la posmodernidad de Michel Maffesoli aclara los fenómenos sociales de una manera muy distinta a como lo hace la teoría general de la posmodernidad. Porque parten de axiomáticos distintos. Por axioma entiéndase un supuesto indemostrable, pero que es útil desde el punto de vista de la investigación. En el caso de Maffesoli, el supuesto es que los hombres actúan más por emoción que por razón y que ello es característico de la posmodernidad, la que se vive en donde los racionalismos han llegado a sus extremos. Esto, según él, es más evidente en los países más desarrollados económicamente de Occidente. Lo presenta como algo cíclico, algo que vuelve, que emerge y no como algo que ya está y se resiste a desaparecer como ocurre en las sociedades tradicionales como las nuestras en América Latina.

Para Raymond Boudon, en cambio, los fenómenos sociales son el resultado de acciones, de comportamientos colectivos racionalizados y en ese sentido se tiene que, metodológicamente hablando, considerar la razón como el aspecto más importante del análisis. 


\section{La fuente de inspiración epistemológica}

Raymond Boudon se inspira de Max Weber, y en particular de su tipología de la acción social. Si recordamos, Max Weber reconoce cuatro tipos de acciones, de comportamientos, uno es determinado por la racionalidad instrumental, el segundo por la racionalidad axiológica, el tercero por la tradición y el cuarto por la emoción o lo afectivo (Affektuel). Esto lo señala en las primeras páginas de Economía y sociedad (1995). Recordemos que la racionalidad instrumental es la que los hombres emplean cuando se plantean un objetivo y piensan en los medios que más les conviene movilizar para lograr ese fin, ese objetivo. Como padre de familia, ¿qué es lo que más me conviene ofrecerle a mi hijo como educación para que viva si no igual, mejor que yo? ¿Costearle una carrera larga o una carrera corta, técnica, por ejemplo? La decisión tendré que tomarla en base a un cálculo que integre los costos y beneficios en ambos casos.

La racionalidad axiológica, en cambio, es la que los hombres emplean cuando actúan con apego a valores y no a utilidades o beneficios materiales. Los cristeros que morían gritando viva Cristo Rey frente a un pelotón de fusilamiento expresaban con ello que morían por un ideal. Los árabes saudís que se inmolaron en las torres gemelas de Nueva York, lo hicieron igualmente por apego a un ideal.

Las acciones que hacemos por apego a la tradición, no son racionales, según Weber, las hacemos por costumbre, ir al panteón a ver a nuestros muertos, bautizar, etc. Lo emocional lo reconocemos cuando los hombres se dejan llevar por la emoción, el gusto, la pasión, el placer, etc. Hablamos de comportamientos no racionales.

Pues bien, de todos estos tipos de acción, Max Weber dice claramente, en su Economía y Sociedad, que es la racionalidad instrumental y la racionalidad axiológica las que motivan con más frecuencia la acción social. De lo cual se infiere que son estas 
Max Weber, entre relativismo e individualismo metodológico: hacia un trabajo de aplicación conceptual al caso de los mexicanos inmigrantes de los Estados Unidos - Rafael Arriaga Martínez

dos racionalidades que hay que identificar en el análisis de los fenómenos sociales.

Ahora bien, Michel Maffesoli no ignora el interés desmedido que Max Weber le concede a la racionalidad como tipo de conducta. Lo reconoce como el mejor enfoque para comprender la mentalidad existente en las sociedades modernas, la que se difunde en Occidente y América del Norte a lo largo de los siglos XVII, XVIII, XIX y la mitad del siglo XX. El problema es que los individuos de hoy en día, según Maffesoli, son cada vez menos racionales y ello hace que se estructuren fenómenos que ya no se pueden analizar, partiendo del supuesto que los hombres son racionales (Maffesoli, 2010a:18). Sostiene que estos fenómenos llevan el sello de la emoción e incluso la histeria y se reconocen en el interés creciente que la gente le profesa a las cosas de este mundo y las ganas de vivir el momento, ahora, y no en función de un proyecto de vida. En países como Estados Unidos, Canadá o Francia, impresiona ver a los jóvenes que apenas empiezan a trabajar y ya piensan en asegurar su retiro, a preocuparse si cotizan o no cotizan para ese retiro que vendrá en 30 o 40 años. Esa preocupación cansa, quita el sueño, estropea el momento que se vive ahora, los hace infelices. El modo de vida racional agota, satura, desespera. La desesperanza, dice Maffesoli en alguna parte de su obra (2004), invita al desfogue, a la entrega de emociones que son efímeras y eternas desde el momento que se busca experimentar esa emoción con intensidad, a través de la relación con los demás, la charla, el juego, el amor, la contemplación de la naturaleza, el chateo, el voyerismo cibernético, etc., etc.

\section{De la emoción como axiomático al reencantamiento del mundo}

Pues bien, con lo emocional, lo afectivo o affektuel de acuerdo al vocablo alemán, Maffesoli nos habla de una disposición hacia el mundo que encanta o más bien reencanta, si consideramos como real el desencantamiento que, de acuerdo a Weber, sufrió el mun- 
do como consecuencia de la extensión de la intelectualización y la racionalización durante los tiempos de la modernidad. Si el desencantamiento del mundo está "ligado a la descalificación de este mundo en provecho de un mundo mejor (Maffesoli, 2010b: 241), la vida centrada en el presente, la reencanta". Para Maffesoli se descalifica el valor de las cosas de este mundo desde el momento que nos sacrificamos hoy para tratar de vivir un mañana mejor, como por el que lucharon los puritanos de los Estados Unidos al trabajar arduamente para rendirle gloria a Dios aquí en la tierra.

Ahora bien, ¿de dónde viene esta actitud de sacrificio? De la idea de la salvación espiritual, dice. Pensar en el futuro, es pensar en Dios, el día que estaremos con Dios, en la ciudad de Dios como lo expresara San Agustín. Estamos de paso, se dice todavía hoy, las cosas de este mundo no valen comparándolas con la vida que Dios nos tiene reservada junto a él. Los calvinistas y en particular los puritanos de Estados Unidos participan de la misma ilusión, la de construir la ciudad de Dios, pero sólo que en lugar de proyectarla sobre el cielo la proyectan sobre la tierra, abriendo con ello la posibilidad de probar en la tierra, algún día, las mieles del cielo. Pero esto, la posibilidad de construir la Nueva Jerusalén en el nuevo mundo, no es más que una proyección, en el sentido de Carl Jung, la proyección de un ideal, de un sueño, pero por otra parte, también la negación del mundo tal cual es. El deber ser de esos puritanos era: debemos trabajar para transformar el mundo en el sentido de ese ideal, y en ese sentido, subrayo la palabra sentido, trabajaron las comunidades teocráticas de Massachusetts y ese sentido se institucionalizó y se propagó a través de las instituciones del Estado una vez secularizado. Es de esta manera que se constituye el deber-ser de la modernidad, el de trabajar siempre en el sentido de un proyecto. Si ayer fue la ciudad de Dios la que absorbía las energías colectivas, ahora, en los tiempos de la modernidad, es la ciudad perfecta. De esa manera se le pierde el sentido a las cosas que hacen perder el tiempo, como la contemplación de un atardecer, porque el tiempo es di- 
nero. Time is money, dicen en Estados Unidos. Está claro que desde el momento que se racionaliza el mundo bajo el aspecto del cálculo y la utilidad se llega al desprecio y el desencantamiento del mundo. Se le desacraliza. Se le pierde el respeto. Nos desarraiga emocionalmente.

La vida centrada en el presente, en cambio, la reencanta. La reencanta porque revalora las cosas de este mundo, sacraliza las relaciones sociales (Cf. Maffesoli, 2000:47). La fuerza con la que los hombres se apegan a las costumbres y las creencias religiosas y populares, como es el caso de los inmigrantes con respecto a la tradición y la confianza en la familia, la parentela o los curanderos, no son más que expresiones de esta sacralización, manifestaciones indiscutibles del reencantamiento del mundo que se opera en las sociedades modernas expuestas a la irrupción de los valores portados por los inmigrantes.

\section{Racionalidad, desencantamiento del mundo e irreversibilidad}

Para Raymond Boudon el desencanto del mundo es un proceso irreversible, no hay vuelta atrás, no puede haber reencantamiento como lo sostiene Michel Maffesoli.

Para Raymond Boudon, el hecho de creer o no en algo, tiene un registro racional cognoscitivo. Y lo demuestra apoyándose en un ejemplo muy conocido de Max Weber (Cf. Weber, 1995, I: $145,146)$. Boudon observa que si la lluvia que provoca el brujo con su ritual es tan mágica a los ojos de su público es porque estos creen en la existencia de un mundo gobernado por fuerzas sobrenaturales y la influencia que tiene el brujo sobre estas fuerzas. Para el hombre moderno en cambio, la lluvia es un fenómeno atmosférico que la meteorología se ha encargado de explicar científicamente. Digamos que el desencantamiento del mundo es un proceso que avanza con el conocimiento del mundo y la liquidación con ello de las explicaciones mágicas o metafísicas. Para 
Raymond Boudon, es un proceso irreversible debido a que el conocimiento, a través del cuestionamiento de los procesos sociales y naturales despoja de carisma al mundo, adelgaza la concepción de un mundo gobernado por fuerzas sobrenaturales. Por carisma entiéndase aquí la creencia en la existencia de poderes sobrenaturales que se manifiestan a través de los hombres y la naturaleza. Pero atención: aquí el conocimiento no es el que nosotros en lo individual tenemos de esos procesos sociales y naturales. Podremos no saber cómo se forman las nubes y se genera la lluvia, pero saber que ese conocimiento existe y que la ciencia lo explica. Desde el momento que un fenómeno deja de ser un enigma, un misterio, se liquida la existencia de una explicación metafísica, la creencia, por ejemplo, que detrás de todo eso se encuentra una fuerza sobrenatural y que hay personas que con su poder, con su carisma, las pueden controlar. El conocimiento científico contribuye a desmitificar el mundo que es otra manera de referirnos al desencantamiento del mundo.

Para Boudon, el desencantamiento del mundo se inscribe dentro de un marco evolucionista. Bajo esta perspectiva teórica se puede fácilmente considerar la integración de los inmigrantes mexicanos como una posibilidad complicada pero no menos real a largo plazo. La posibilidad de mejoramiento en los niveles de instrucción, por ejemplo, ayudaría a los inmigrantes a depurar de supersticiones sus creencias religiosas y suscribir a una concepción más pragmática de la religiosidad como la que practican los protestantes y los católicos estadounidenses. Hablamos de una religiosidad más centrada en la moral que en los dogmas y despojada, como lo demuestran ciertas encuestas, de las creencias más imaginadas como es la idea de infierno, demonio, etc. (lnglehart, Basanez y Moreno, 1998). Desde este punto de vista el desencantamiento del mundo afectaría, tarde o temprano y de manera ineluctable la religiosidad popular de los inmigrantes mexicanos; la cortaría de una concepción del mundo gobernado por la providencia y fuerzas sobrenaturales y con ello la posibilidad de constituirse en fuente de este proceso de reencantamiento 
del que habla Maffesoli. Vemos pues que para Boudon el desencanto del mundo es un proceso irreversible gobernado por la racionalidad.

\section{Acerca de las acciones presenteístas, reencantadas dictadas por la emoción y la histeria}

De la tipología de la acción social de Max Weber, que mencionábamos en un principio, Michel Maffesoli ignora la racionalidad instrumental, la que hace que la gente piense en un objetivo y en los medios apropiados para alcanzar ese objetivo. Es esta racionalidad la que, a sus ojos, es responsable del desencantamiento del mundo, de que se desprecie y se saquee la naturaleza y de paso se tiranice a los hombres en el nombre de la productividad, capitalista o socialista. La ignora porque, como ya lo habíamos dicho, la gente es cada vez más emocional que racional. Es por eso que de esa misma tipología, retiene la que se realiza bajo el impacto de la emoción, pero no descarta del todo la determinada por la racionalidad axiológica, la cual, de acuerdo a Weber, se observa cuando los actores actúan con apego a valores. Tenemos pues que Michel Maffesoli fusiona lo afectivo, digamos lo emocional, con lo axiológico o la importancia que tienen los valores para los hombres.

Michel Maffesoli retoma de Nietzsche la idea de la alternancia de lo emocional y lo racional como factor estructurador de la realidad social a lo largo de la historia humana para considerar el desencantamiento del mundo como un proceso de racionalidad que se acaba y lo emocional como algo que emerge de nuevo.

¿Pero en virtud de qué se acaba un ciclo de la historia humana y empieza otro?: en virtud de lo que Maffesoli llama saturación, la saturación de los valores de la modernidad que ya no son capaces de asegurar la cohesión social y la vitalidad que requiere el cuerpo social para su desarrollo. Porque Para Maffesoli la crisis por la que atraviesa la modernidad no sólo es económica, política 
y social, es también espiritual. La gente se ensalvaja en los tiempos de la posmodernidad, se vuelve instintiva, casi animal, para bien o para mal (Cf. 2011b:95). Para Michel Maffesoli las cosas son como son, nos guste o no nos guste, volens nolens, como él dice. Y para el caso evoquemos este ejemplo, que no es muy fino, pero que hay que tomarlo como es, como un despliegue paradoxístico de la posmodernidad.

Todas las campañas de repatriación masiva de indocumentados que hemos conocido hasta hoy han sido precedidas por intensos debates públicos en los que se entremezclan lo emocional con los valores, desatando comportamientos motivados por la xenofobia y con algo más que flota en el aire y que mucha gente respira: el ideal de una nación fiel a los valores heredados de los puritanos. El que, naturalemente, se tiene que defender, eliminando las impurezas culturales, a la ocurrrencia la que representan los mexicanos con su cultura. Recordemos las razias que realizaron los minuteman contra los indocumentados, en Aeropuertos como el de San Diego, en California. Son acciones presenteístas, diríamos en el lenguaje de Michel Maffesoli, porque llevan el sello de la emoción e incluso de la histeria, de algo cuya importancia tiene que ver menos con la solución del problema de la inmigración de indocumentados que con la teatralización de la acción. Se podría decir entonces que lo más importante es el contacto de unos con otros, la catarsis, la emoción compartida, el sentimiento que el problema se resuelve en ese instante, como por arte de magia, de manera encantada. Pero esto no es sólo así para los que participan en la cacería. La publicidad -la que hace la opinión publicada- hace que la opinión pública se dispare emocionalmente, en sentidos distintos. Cualquiera que sea el sentido de la reacción, a favor, en contra, y cualquiera que sea la argumentación, la escena es la misma, la de la pasión, la de la histeria. De nueva cuenta, aquí lo importante para los hombres en los tiempos de la posmodernidad es vibrar de emoción, sentir que se vive intensamente el momento. Para Maffesoli es el instante eterno, el presenteísmo. Por eso propone que se reorien- 
te la investigación, que ésta se preocupe más por el estar-juntos que por el deber-ser porque a lo uno lo determina la emoción y a lo otro la razón. Para Maffesoli, la emoción en los tiempos de la posmodernidad, es el pegamento del lazo social, lo que explica la agregación, las relaciones sociales.

\section{Acerca de la tesis del desencantamiento del mundo como un proceso de selección racional e universalización de los valores.}

Raymond Boudon por su parte minimiza el papel de lo emocional en la estructuración de las relaciones sociales (2003a:97; 2003b:53). Parte de un axiomático que integra de manera orgánica las motivaciones instrumentales con las motivaciones axiológicas. "Yo quiero ganarme la vida con el sudor de mi frente", ésta es una sentencia ordenada por la racionalidad instrumental y la racionalidad axiológica. La racionalidad instrumental me dice que debo trabajar para ganarme la vida, y la racionalidad axiológica me ordena que ese medio sea bueno, sea honesto, que no afecte a nadie. En la cámara de representantes, para poner un ejemplo que vaya con nuestro tema, se habla siempre de maximizar los obstáculos relativos al cruce de la frontera por parte de los indocumentados porque se sabe o se parte del supuesto que vienen a Estados Unidos sabiendo que es más lo que ganan que lo que pierden, que los costos de la emigración se amortizan con el tiempo. Pero ello no se discute sin que se considere la dimensión axiológica del problema. Siempre habrá alguien que cuestione las medidas preguntando: ¿Hasta qué punto es moralmente justo y legítimo convertir la inmigración clandestina en una empresa incosteable, si vemos que los medios empleados atentan a la dignidad humana y contra la vida misma de los inmigrantes indocumentados? Todo parece indicar que existen actitudes que pudieran traducir tales razonamientos. Sorprende por ejemplo el respeto de la patrulla fronteriza a la existencia de aguajes en los desiertos de la frontera con México y ello pese a la hostilidad 
de los minutemen y el público que los apoya. "Hagan su trabajo señores, pero no los dejen morir en el desierto", pudiera ser el razonamiento de No more Death, la organización que presiona para que la patrulla fronteriza actúe con humanismo.

En un sentido opuesto a la concepción de la relatividad de los valores, de la suscripción a los valores según el humor y el ánimo de los individuos, Boudon postula la existencia de la universalidad de los valores. Esta universalización de valores sería portada a través de un proceso de racionalización y desencantamiento del mundo que no tiene fin. Boudon retira de Weber, además de la noción de desencantamiento del mundo, el concepto de racionalización difusa o la idea según la cual los valores se difunden a través de mecanismos racionales de selección (Boudon, 2003b: 136) y no por imitación como lo sostiene Maffesoli y detrás de él Gabriel Tarde (1993). Pongamos un ejemplo enigmático, sobre todo para quien, en países como México, suscribe a la idea que trabajando duro sólo se alcanza a sobrevivir. ¿Por qué los inmigrantes, en Estados Unidos, como lo demuestra una encuesta realizada por Pew Hispanic Center Research (2012) creen, e incluso en mayor proporción $(60 \%)$ que los estadounidenses, que trabajando duro se puede llegar hasta donde uno quiera e incluso hasta llegar a ser rico? La hipótesis sería esta: creen porque experimentan la noción del progreso social y lo constatan al comparar el nivel de vida dejado en México y el alcanzado en Estados Unidos. Es el conocimiento de este hecho que los invita a suscribir a esta idea, a este valor. Pero ello no les impide ser críticos con relación a otros valores que empobrecen las relaciones humanas. O por lo menos eso es lo que podemos inferir de una encuesta en la que se revela comparativamente la proporción de inmigrantes mexicanos que admiran a México (47\%) y Estados Unidos (24\%) por el vigor con el que la sociedad adhiere a los valores familiares (Suro, Brodie, Steffenson et al.: 2002). Se trata de un aspecto relevante a los ojos de la sociedad estadounidense, pues $80 \%$ de ellos perciben a los mexicanos como un grupo cimentado en valores familiares (strong family values) (Kohut y Suro, 2006). 
A la individualización y el relajamiento de los lazos familiares característicos de la sociedad estadounidense, los inmigrantes mexicanos le oponen el sentido de la familia y la solidaridad familiar.

Podríamos decir, que si los mexicanos rechazan el individualismo y el egoísmo que caracteriza las relaciones intrafamiliares entre los estadounidenses, es porque necesitan de la familia para sobrevivir. Perciben los lazos familiares de solidaridad como útiles y funcionales. Pero esta adhesión se da entre los estratos más desfavorecidos que es la categoría en donde se encuentra una buena proporción de inmigrantes. Porque para las clases medias, la solidaridad familiar es resentida más como una carga que como beneficio.

La idea de la irreversibilidad del desencantamiento del mundo y de los valores por vía de consecuencia, presupone que los inmigrantes evalúan sus propios valores comparándolos con los de la sociedad receptora. Presupone también que eligen los valores a la luz de lo que les es más útil, lo que más les ayuda a vivir mejor. Este proceso cognoscitivo es clave porque desarma el conflicto de valores que los inmigrantes experimentan en el curso de su integración a la sociedad receptora. Para Raymond Boudon la guerra de los dioses, el politeísmo de valores del que habla Weber (Cf. 1959), es eso: un conflicto, sí, pero superable (Boudon, 2003b:163, 319) y no insoluble como lo plantea Maffesoli (1985:169). Desde este punto de vista la integración de los inmigrantes es vista con optimismo, como un proceso complicado pero seguro a la larga.

\section{De la guerra de los dioses como un conflicto insoluble a la horizontalización equilibrada de la sociedad}

Para Maffesoli en cambio, no son los individuos que seleccionan los valores. Es el espacio que los determina (1985:146). Los hombres no hacen más que acomodarse, ajustarse al espacio. Son 
"ajustes" a través de los que se construyen y reconstruyen los valores. Porque allí, en ese espacio, la casa, el barrio, el gueto, digámoslo con las palabras de "se aprende lo que hay que decir, hacer, pensar, querer" (2004: 217). Pero como el espacio en el que les toca vivir a los inmigrantes mexicanos, no es el mismo en el que viven los miembros de la sociedad receptora e incluso otros grupos de inmigrantes, los ajustes tienen que ser distintos y los valores que surgen de ese espacio también tienen que ser distintos. $\mathrm{Y}$ en este proceso todos defienden su espacio, sus valores, su identidad, en una palabra. Y lo hacen con pasión porque es algo instintivo, algo casi animal. Tenemos pues que al llegar a este nuevo espacio que es los Estados Unidos, los inmigrantes defienden con pasión su identidad y sus valores, generando con ello un conflicto de valores, una guerra de dioses inexpiable (1985:169). Una guerra que no tiene solución y sin embargo y por paradoja, las sociedades receptoras de inmigrantes ganan, se enriquecen culturalmente, no pierden como lo sugiere Samuel Huntington (2004), ese intelectual estadounidense que sostiene la idea de la incompatibilidad de la cultura mexicana con la estadounidense. Con la inmigración, digamos esto razonando en términos de la teoría de la posmodernidad, las sociedades modernas se multiculturalizan, se posmodernizan, favoreciendo con ello la guerra de los dioses, la lucha inexpiable entre los grupos comunitarios o minorías. Pero también se favorece la posibilidad a largo plazo de una relación entre estos grupos más equilibrada e integrada (1985:169). Equilibrada porque al atomizarse la sociedad en grupos comunitarios el poder de la sociedad vertical -el poder de coerción que se expresa a través de sus instituciones- se horizontaliza, se transforma en potencia, germina y crece dentro de cada una de las tribus. Esto significa que el Estado deja de ser un poder desde que pierde la posibilidad de imponerse sobre la sociedad con sus ideas, con sus valores, con sus creencias. La sociedad se libera del gran proyecto, el que representa la sociedad ideal, la que unos cuantos quisieran que fuera, una e indivisible, como la que imaginaron los puritanos a bordo del Mayflower y 
Max Weber, entre relativismo e individualismo metodológico: hacia un trabajo de aplicación conceptual al caso de los mexicanos inmigrantes de los Estados Unidos - Rafael Arriaga Martínez

sus descendientes. Es el imaginario colectivo de unos cuantos el que se expresa a través de todas estas grandes ideas. Un imaginario colectivo con poder vertical.

La potencia se antepone al poder en este sentido de que el poder es el que se ejerce de manera vertical y la potencia se ejerce de manera horizontal, y ella corresponde a algo que está en todos y se puede compartir: las emociones, los anhelos, los sueños, lo onírico (2004:27). Es una riqueza inmaterial, ilimitada, todo lo contrario de lo que es el dinero, el conocimiento, la política, todo lo que pueda conferir poder. Ello explica la solidaridad como algo que crece entre las tribus.

En los países de inmigración la solidaridad tradicional de las comunidades de inmigrantes coexiste con las nuevas formas de solidaridad emergentes. Estas por lo general son más sofisticadas, como las que se expresan a través de las redes sociales cibernéticas.

Para Michel Maffesoli en los tiempos de la posmodernidad no es el deber-ser que motiva a los hombres a ser solidarios los unos con los otros, es el querer-vivir, el estar juntos (2010b:17). Aclaremos esto con dos ejemplos que nos parecen bastante ilustrativos. Uno ocurre en Westwood, un barrio acomodado de Los Ángeles, y el otro en un barrio de inmigrantes mexicanos: el Este de Los Ángeles. Las escenas son protagonizadas por jóvenes que se ayudan en sus mudanzas. En Westwood no son los miembros de la familia que se ayudan, ni mucho menos los vecinos. Los personajes en escena surgen del contacto y la coordinación a través de redes sociales cibernéticas. No se conocen. Nunca se habían visto. El encuentro es puntual y en el entendido de que a cambio de la ayuda no habrá remuneración. Se ayuda por ayudar. No es un acto que se pueda comprender racionalmente, diría Maffesoli, ni por el lado de la racionalidad instrumentación ni por el lado de la racionalidad axiológica: no lo hacen por dinero o reconocimiento ni lo hacen por obligación moral o porque deben hacerlo. Están allí, porque ayudar por ayudar ofrece la oportuni- 
dad de estar junto a otros, de vibrar de emoción en grupo, porque se hace algo inédito: ayudar a alguien de manera desinteresada, algo que gratifica emocionalmente, que ofrece la oportunidad de sentir la vida a través de la relación con los demás. A esto Maffesoli lo define como una forma particular de correspondencia: la alteridad social (Cf. Maffesoli, 1985:155), porque la relación social se enraíza en el inconsciente colectivo. El intercambio es global, incluye un beneficio inmaterial que se reparte entre todos. Formas de solidaridad como ésta expresan lo que Maffesoli define como potencia societal. Se trata de un concepto que Maffesoli plantea en El tiempo de las tribus (2004:27), en el capítulo titulado "Encontrar las palabras".

En el este de los Ángeles, son los familiares y los vecinos que participan en la mudanza. La alteridad social que se establece es tradicional, una forma de relación venida a menos en las sociedades modernas. Se diría de entrada que es la precariedad, la necesidad material de los otros la que explica el lazo social. Pero eso sería considerar sólo la parte emergente de la psicología humana, la que le corresponde al racionalismo, e ignorar lo que Maffesoli llama centralidad subterránea, la capa freática de la existencia humana, la que conecta con los arquetipos, los que, de acuerdo a Jung, condicionan el imaginario y se expresan a través de los símbolos.

En términos empíricos, los encuentros solidarios permiten conocerse unos a otros, son nuevas formas de encuentro que se substituyen a la solidaridad familiar y de vecinos. Esta nueva forma cibernética de solidaridad, es, como ya lo hemos dicho antes, la salida, el poro por donde respiran las nuevas tribus, las tribus de la posmodernidad y entre las que se cuentan aquellas que perdieron el calor de la familia tradicional y su ambiente natural, recreativo, como consecuencia de la racionalización del tiempo y el confinamiento consiguiente de la vida familiar a la esfera de lo privado.

Valdría la pena hacer una precisión en lo que respecta a la noción de tribu. En Michel Maffesoli este no sólo se aplica a las 
comunidades formadas a partir de la inmigración. Considera todos aquellos grupos que se forman en torno a una pasión, un gusto, una emoción. Desde este punto de vista, la identidad étnica y la solidaridad que le acompaña funcionan más por empatía emocional que por motivaciones de índole puramente racional o axiológica. La empatía permite sentir al otro, identificarme con él, ponerse en sus zapatos, si se pudiera decir así; y a partir de allí reconocerse en el otro con un mismo sueño, una misma aspiración, el recuerdo de un lugar dejado en el país de origen, de una cultura que los representa y que se construye ahora y aquí. De allí también la recomendación metodológica de explorar el imaginario colectivo -el cielo de las ideas, de las fantasías y las ilusionesa través del tipo ideal y la empatía. La emoción como axiomático, como resorte de la acción, define toda clase de grupos en donde se comparte una pasión. Para Maffesoli es la pasión la que explica el lazo social, la cohesión social, la vida en sociedad... y el reencantamiento del mundo... y la guerra de los dioses.

\section{Conclusiones}

El lector podrá observar los contrastes notables que existen entre ambas teorías, en términos conceptuales y el significado que le dan a los aspectos de la realidad social aclarados. La teoría general de la racionalidad es más conceptual, o para ser más precisos, su lenguaje es simplemente conceptual, a diferencia de la teoría de la posmodernidad. Michel Maffesoli rechaza los conceptos, porque para él la sociología no es una ciencia, no explica nada (1985), los conceptos son estériles, observa, ofrecen sólo una explicación truncada de la realidad (Cf. Maffesoli, 2000: 11). Es por eso que prefiere las nociones, las metáforas, las figuras emblemáticas, como cuando habla de Dionisos, para referirse a la emoción, o de Prometeo para hablar de la razón, o el niño eterno para indicar que desde el fondo de nuestra conciencia se agita algo y nos mueve a imitar a los jóvenes en sus maneras de ser, de vestir, de hablar, etc., que la emoción es una axiomático de inves- 
tigación válido porque no sólo afecta a los jóvenes, que el niño eterno aglutina a las masas y que Prometeo, el tótem del adulto serio, productor y reproductor, como diría Durkheim, atrae cada vez menos gente. Las nociones, las palabras llanas, le parecen necesarias para describir no precisamente la realidad social, sino lo Real. La realidad social se expresa a través de la política, la economía, lo social, lo racional, mientras que lo Real expresa lo racional y lo no racional: los sueños, las fantasías, los anhelos, el imaginario colectivo, todo lo que la ciencia positivista desprecia. Los desprecia porque son inobservables, porque son procesos psíquicos invisibles que recorren el cuerpo colectivo de manera subterránea y afloran a través del símbolo, el mito y la imagen; del imaginario, para expresarlo en una sola palabra. En El tiempo de las Tribus (2004:39) se encuentran una frase que traduce esto que acabamos de plantear: "cavar profundo y apegarse a la superficie de las cosas". Es una lección de método: saber comprender lo que está a la vista, describir lo real a partir de lo irreal, lo que está en el fondo de uno mismo. Sin duda que hay que cavar profundo para comprender el sentido, el significado que tiene la imagen de la virgen de Guadalupe para un inmigrante mexicano, que no es de superficie, no es racional como lo sostiene Raymond Boudon. Tiene una profundidad que emociona misteriosamente. La emoción resentida bajo la forma de misterio indica la presencia de una energía subterránea. Para Michel Maffesoli esa energía subterránea gobierna el mundo de una manera enigmática. De allí la noción de centralidad subterránea (Maffesoli, 2009a:27, 28).

Decíamos que Michel Maffesoli prefiere las nociones, las metáforas, las figuras emblemáticas, como cuando habla (digámoslo una vez más, aunque no lo hayamos mencionado en nuestra exposición) de Dionisos, para referirse a la emoción, o de Prometeo para hablar de la razón. Porque le permiten describir los fenómenos sociales a partir de procesos arquetipales. Es una cuestión de método y no de estilo o gusto literario. Un método capaz de abordar los objetos de estudio desde una perspectiva integral, que tome en cuenta la relación estrecha existente entre lo material 
y lo espiritual (Maffesoli, 2011: 20). Tenemos que reconocer que en el imaginario y el presenteísmo existe "una impulsión vitalista que alía lo material y lo espiritual", observa MM en su reencantamiento del mundo (2009b:39). Y como en el caso de cualquier otra metodología, Michel Maffesoli fundamenta su enfoque en una epistemología que se nutre mucho de la sociología comprensiva de Max Weber. Se trata evidentemente de una lectura polémica, si tomamos en cuenta que hay autores como Raymond Boudon que no la comparten. Para Raymond Boudon las descripciones holistas son inverosímiles, porque rayan en la metafísica desde que postulan la existencia de una psicología humana insondable.

Muchas gracias.

\section{Bibliografía}

Arriaga, Martínez Rafael (2012): “Max Weber: entre el relativismo y el individualismo metodológico", en Revista Culturales, junio-diciembre 2012, No. 16.

Boudon, Raymond (2003 $)$ : Y a-t-il encore une sociologie. París, Editions Odile Jacob.

Boudon, Raymond (2003b): Raison, Bonnes raisons. París, Presses Universitaires de France.

Huntington, Samuel (2004): ¿Quiénes somos? Los desafíos de la identidad nacional estadounidense, Barcelona, Paidós.

lnglehart R., Basanez M., Moreno A. (1998): Human Values and Beliefs: A Cross-Cultural Sourcebook, Ann Arbor, The University of Michigan Press.

Maffesoli, Michel (1985): La connaissance Ordinaire, Précis de sociologie compréhensive. París, Méridiens Klincksieck.

Maffesoli, Michel (2000): Le temps des tribus. Le déclin de l'individualisme dans les sociétés postmodernes. ( $3^{\text {a }}$ Edición). París, La table ronde.

Michel Maffesoli (2004): El tiempo de las tribus. México, Siglo XXI.

Maffesoli, Michel (2009a): Essais sur la violence, banale et fondatrice. París, CNRS Editions, 3a edición. 
Maffesoli, Michel (2009b): Le réenchantement du monde, París, Perrin.

Maffesoli, Michel (2010a): Le temps revient. Formes élémentaires de la postmodernité. París, Editions DDB.

Maffesoli, Michel (2010b): La République des bons sentiments et autres écrits de combat. París, Editions Embrasure.

Maffesoli, Michel (2011): La passion de l'ordinaire. Miettes sociologiques, París, CNRS Editions.

Pew Research Center (2012): “When labels don't fit: Hispanic and their views of indentity". En línea: <http:/ / www.pewhispanic. org / 2012/04/04/when-labels-dont-fit-hispanics-andtheir-views-of-identity/>.

Tarde, Gabriel (1993): Les lois de l'imitation. París, Kimé Éditeur.

Weber, Max (1959): Le savant et le politique. París, Editions Plon.

Weber, Max (1995): Economie et Société, I. París, Editions Plon.

Kohut, Andrew y Roberto Suro (2006): "Non consensus on immigration problem or proposed fixes. America's immigration quandary". En linea: http:/ / pewhispanic.org/files/reports/63.pdf

Suro, Roberto; Mollyann, Brodie y Annie Steffenson et al. (2002): National Survey of Latinos. En línea: http:/ / pewhispanic.org/ files/reports/63.pdf. 